\title{
ESTIMATION OF ANNUAL RUNOFF AND PEAK FLOW AT NAZANIN CATCHMENT IN ERBIL, KURDISTAN REGION USING DIFFERENT APPROACHES
}

\footnotetext{
${ }^{1}$ Yaseen W. Aziz, ${ }^{2}$ Mariwan A. Hama Saeed ${ }^{*}$ and ${ }^{3}$ Shaheen S. Ahmed ${ }^{1}$ Department of Water Resources, College of Engineering, University of Salahaddin, Erbil, Iraq

${ }^{2}$ Department of Geology, College of Science, University of Salahaddin, Erbil, Iraq

${ }^{3}$ Department of Water Resources, College of Engineering, University of Salahaddin, Erbil, Iraq

*Email: mariwan.hamahsaeed@su.edu.krd

Received: 7 July 2020; accepted: 11 October 2020
}

\begin{abstract}
Runoff is excess rainfall or a portion of rainfall that flows over the watershed. In un-gauged streams, due to lack of data, many methods are used for runoff estimation. In this paper annual runoff and peak flow of Nazanin watershed were estimated at Nazanin Dam location using different methods. Soil Conservation Service (SCS) method, basin relation, (Hydrologic Engineering Center-Hydrologic Modeling System) HEC-HMS and Hydrologic engineering center (HEC-1) models were provided. The Watershed Modeling System (WMS) package was used for watershed delineation and computation of curve number. The area of Nazanin catchment is $72.14 \mathrm{~km}^{2}$, and the composite curve number is 81.3. The results of average annual rainfall estimated using the basin relationship method are more than that obtained from SCS method. The results of peak flood discharge for different return periods using different approaches such as SCS method, HEC-HMS and HEC-1 models are very close. But the results of basin relation are lower than SCS method. From the results of comparison, it was observed that HEC-HMS and HEC-1 models can be used for generation flood hydrograph at ungagged watershed.
\end{abstract}

Keywords: Rainfall; Runoff; Watershed; Stream

\section{INTRODUCTION}

Runoff is usually generated from rainfall after infiltration a part of rainfall and the area become saturated. Mainly rainfall-runoff is a process affected by many nonlinear factors such as catchment characteristics, rainfall intensity, duration and soil moisture (Taleli et al, 2010). The temperature data since 1960 till 2007, rainfall and evaporation data since 1960 till 2008 and 1970 till 2008, respectively, indicated an increase temperature of about $5^{\circ} \mathrm{C} / 47$ years and an increase in evaporation rate with a decrease in the rainfall rate. (Awadh and Ahmad, 2012; Awadh and Abdul Al-Qhani, 2014). In many cases lack or insufficient data is also a major problem 
for runoff estimation. Estimation of peak discharge and runoff hydrographs in any catchment area are used for a variety of purposes in hydraulic structures such as spillways and flood control structures. Many methods are used for estimating runoff such as; unit hydrograph empirical methods. In ungagged catchment area due to lack of data; empirical formulae are used for estimation runoff. SCS method is widely used for estimation direct runoff from rainfall (Shi et al, 2009). Sajikumar and Thandaveswara (1999), provided some models for rainfall-runoff modeling using artificial neural network, they indicated that nonlinear models have higher accuracy and liner models cannot be recommended for use in a basin with prominent non linearity. Steenhuis et al (1995) revised SCS approach for predicting runoff over a catchment area good agreement was found by comparing its results with observed runoff. Yannopoulos et al. (2006) indicated that the dimensionless unit hydrograph of SCS gives reliable results because the method needs only the $\mathrm{CN}$ and the lag time. Zhang et al, (2008) used SWAT model combined with three different snowmelt algorithms for runoff simulation. They suggested using SNOW17 model for modeling un-gauged basins, while SNOW17 and temperature-index plus elevation band for gauged basins could predict better results of runoff simulation. Tsheko (2006) concluded that SCS method underestimate in prediction of mean annual runoff at the first watershed and overestimate at the second one. Paudel et al. (2011) compared between HEC-HMS model and fully distributed model (GSSHA) to analyze the influences of land use change on peak discharge and runoff volume. It was concluded that GSSHA is better to predict peak flood discharge and runoff volume for changes of land. Younis et al, (2014) HEC-1 model based on SCS method could accurately predict peak discharge when compared with the observed data. Hoseini et al. (2017) compared different models in WMS such as TR-20, TR55 and HEC-1 for predicting flood discharge; it was observed that TR-55 yields better results than others.

The watershed modeling system (WMS) package is a geographic information system with hydrological applications, it combines GIS spatial data with hydrological models. In the present study, total annual volume of runoff and peak discharge for different rainfall at Nazanin watershed were estimated using basin relation, S.C.S method and HEC-HMS model.

\section{THE STUDY AREA}

The study area is Nazanin catchment located at $45 \mathrm{~km}$ northeast of Erbil city (448533.69 E, 4022190.48 N and 459906.96 E, 4009636.30 N) (WGS-1984-UTM -ZON-38N) (Fig. 1). The area is within wet zone, most of rainfall occurs during the period between October to Mid of May. Maximum temperature is close to $40{ }^{\circ} \mathrm{C}$ during July and August and minimum 
temperature is less than $0{ }^{\circ} \mathrm{C}$ during January and February according to Erbil metrological station. Average monthly evaporation for July and August period is about $15 \mathrm{~mm}$ per a day. The catchment area is un-gauged for rainfall measurement and stream flow measurement.

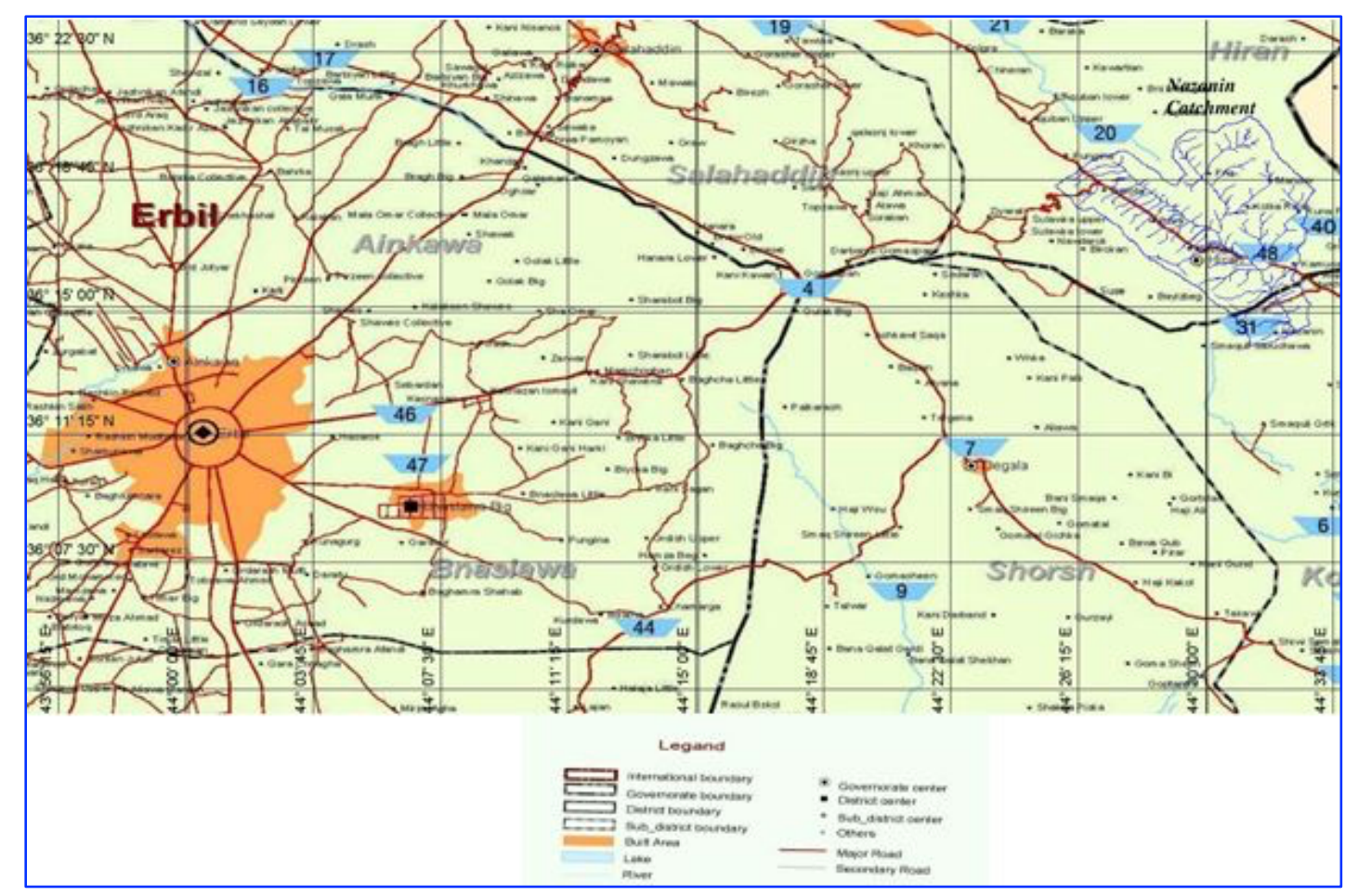

Fig. 1. Location map of the study area

\section{MATERIALS AND METHODS}

\section{Catchment Area Delineation}

The catchment area of the Nazanin dam was delineated using Watershed Modeling System (WMS V. 8.2). The Digital Elevation Model (DEM) image with spatial resolution (30 m) was provided. Global mapper 19 is used for trimming and preparing the DEM image in order to reduce the running tie. The coordinate of the outlet point of the catchment area was obtained using GPS, (459,090.5, 4,010,408.05) (WGS-1984-UTM-Zone-38N).

\section{Deriving Annual Runoff Based on Catchment Area Relationships}

AL-Khazer River is one of the tributaries of Greater Zab, it originates within the boundaries of Kurdistan region. The average rainfall over the catchment area of the river is about $730 \mathrm{~mm}$. A continuous stream flow measurement for the river for 48 years is available. Because the characteristics of the catchment area of AL-Khazer River are almost similar to characteristics of most catchment area of local rivers, so this similarity is used for estimating annual runoff for Nazanin stream. The stream is intermittent stream and one of the attributes of Lesser Zab. 


\section{Soil Conservation Services (SCS) Method}

This dimensionless unit hydrograph was developed by US SCS for uniform rainfall using the assumptions for a triangular hydrograph. To compute runoff for a given precipitation, it is necessary to compute the curve number. A curve number $(\mathrm{CN})$ is an index that represents the combination of a hydrological soil group, land-use and treatment class (Tsheko, 2006). This method is convenient for un-gauged watersheds where stream flow measurement data is not available while the rainfall data and the characteristics of the watershed can be obtained. To compute runoff from rainfall SCS method uses the following equations:

$$
\begin{aligned}
& P e=\frac{(P-0.2 S)^{2}}{(P+0.8 S)} \\
& S=(25400 / C N)-254
\end{aligned}
$$

Where:

Pe: Surface runoff depth in $\mathrm{mm}$

$\mathrm{P}$ : Depth of rainfall (Daily) in $\mathrm{mm}$

$\mathrm{S}$ : Maximum potential retention, starting at the time when the storm begins.

$\mathrm{CN}$ : Curve Number between ( 0 to 100 ). When $\mathrm{CN}=100, \mathrm{~S}=0$ and $\mathrm{Pe}=\mathrm{P}$

$\mathrm{CN}$ depends on many factors such (type of soil at the surface of ground level, moisture content, type of the crop, surface condition of the ground, slope of the land (Heedan et al, 2017).

$\mathrm{CN}$ is obtained from tables where the values apply to corresponding to antecedent rainfall condition II, this condition is an average value for annual floods. According to the factors mentioned earlier SCS method classifies soil to four hydrological soil group (A, B, C, and D) depending on the infiltration rate for condition II. At antecedent moisture content I (AMC-I) range of the moisture content for this case between wilting point to about lower plastic limit this condition is valid at the starting of rainfall. Condition II (AMC-II), this condition is valid when the soil is entirely wet. Condition III (AMC-III), in this condition the soil is at saturate moisture content and soil ability for infiltration is at minimum level and runoff increases. Curve numbers tabulated by SCS method that is apply for normal moisture conditions (AMC II). For other conditions dry (AMC I) or saturate (AMC III) conditions equivalent curve numbers could be computed (Chow et all, 1988).

$$
\begin{aligned}
& C N(I)=\frac{4.2 C N(I I)}{10-0.058 C N(I I)} \\
& C N(I I I)=\frac{23 C N(I I)}{10+0.13 C N(I I)}
\end{aligned}
$$


The nearest metrological station is Salahaddin station, where monthly rainfall is available, while there is daily and monthly data for long period is available at Erbil metrological station. For this reason, Erbil data is taken as index to estimate daily rainfall for the catchment area and daily rainfall data was obtained from this station for the period between 1991 and 2002 and used to obtain daily rainfall over the catchment for the same period.

\section{Estimation of Peak Discharge}

The following approaches and relations were used to estimate peak flow discharge for the catchment area.

\section{Basin relationships with Al-Khazer:}

Al-Khazer can be used as index for all rivers of the region because it originates in the Kurdistan Region and it has a continuous recorded data for long period. Extreme maximum daily discharge of the river for different return periods can be obtained by using Lettenmaier and Burges (1982) Suggestion for Gumbel extreme value method:

$$
\begin{aligned}
& \mathrm{Q}=\text { Qavg }+(0.78 \mathrm{y}-0.45) * \mathrm{~S} \\
& \mathrm{y}=-\operatorname{Ln}(\operatorname{Ln}(\operatorname{Tr} /(\operatorname{Tr}-1)
\end{aligned}
$$

\section{S: Standard Deviation}

Qavg: Average discharge in $\mathrm{m}^{3} / \mathrm{s}$

Tr: Return period

The consultant Engineers (SGREA) performed a study for upper Adhaim catchment area (about $11000 \mathrm{~km}^{2}$ ) with almost similar catchment characteristics of AL-Khazer. They obtained a regression between discharge and the catchment area size. Using the same equation for both basins:

$$
\begin{aligned}
& \mathrm{Q}_{\mathrm{PN}}=26.5 *\{1+\log (\mathrm{Tr} / 100)\} * \mathrm{~A}^{0.59} \\
& \mathrm{Q}_{\mathrm{PKH}}=26.5 *\{1+\log (\mathrm{Tr} / 100)\} * \mathrm{~A}^{0.59} \\
& \mathrm{Q}_{\mathrm{PN}}=\mathrm{Q}_{\mathrm{PKH}} *\left(\mathrm{~A}_{\mathrm{N}} / \mathrm{A}_{\mathrm{KH}}\right)^{0.59}
\end{aligned}
$$

Where:

$\mathrm{Q}_{\mathrm{PN}}=$ Peak discharge for Nazanin basin for return period $\mathrm{Tr}$

$\mathrm{QP}_{\mathrm{KHN}}=$ Peak discharge for AL-Khazer basin for return period $\mathrm{Tr}$

$\mathrm{A}_{\mathrm{N}}=$ Area of Nazanin basin in $\mathrm{Km}^{2}$

$\mathrm{A}_{\mathrm{KH}}=$ Area of AL-Khazer basin in $\mathrm{Km}^{2}$ 


\section{SCS method}

SCS method together with extreme maximum daily runoff in a year peak discharge for different return period was found. Gumbel method was used to predict rainfall for any required return periods. Peak discharge for depth of runoff found considering triangular USC hydrograph.

$$
Q_{p}=\frac{0.207 A P_{e}}{T p}
$$

Where:

$\mathrm{Tp}$ is time to peak (or time of rise of the flood hydrograph) which is equal to the lag time plus half of the storm duration (hour).

$$
\text { Lag time }=C_{t} *\left(\frac{L * L C a}{\sqrt{S}}\right)^{n}
$$

L: length of overland flow, Lca: length of watershed centroid (mile), S: maximum flow slope (ft/mile), n: exponent (0.39), Ct: time to peak coefficient (1.42).

\section{HEC-HMS model}

The WMS packages contain several models for watershed modeling; HEC-HMS is one of them. The HEC-HMS model has been used for estimating peak discharge and volume of runoff at the watershed. It designed for runoff simulation for a wide range of geographic area. The HECHMS has the capability to analyze the watershed hydrology in both lumped and semidistributed (HEC-HMS Mod Clark Method) (Paudel et al., 2011). In lumped model, all of the parameters which impact the hydrologic response of a watershed are spatially averaged together to create uniformity across the basin (Shultz, 2008), while in the case of semi distributed model, losses due to infiltration and runoff for each sub basin are calculated independently to other sub basins. The runoff is converted to sub basin outflow using the same methods as used in the lumped models (Fathy, 2015).

\section{HEC-1 model}

HEC-I is another model in WMS which is developed by US army corps of Engineers. It is designed to simulate the surface runoff resulting from precipitation by representing the basin with interconnected hydrologic and hydraulic components (Oleyiblo and Li, 2010).

\section{RESULTS}

The area of Nazanin watershed $\left(73.14 \mathrm{~km}^{2}\right)$ was determined using WMS (Fig. 2). Samples of soil were taken at different location of the catchment to determine type of soil. Three hydrological soil types were specified which are B, C and D. The study depended on visit site to specify land use and land cover. Several types of land use are determined which are exposed 
rock, cultivated land, pasture land and wood or forest land. According to the combination of topography, land cover and type of soil, WMS calculated the composite curve number of the catchment. The composite $\mathrm{CN}$ for the Nazanin catchment is 81.3 for condition II which is an average value for annual floods, while CN for condition I and condition III is 61.5 and 90.9 respectively.

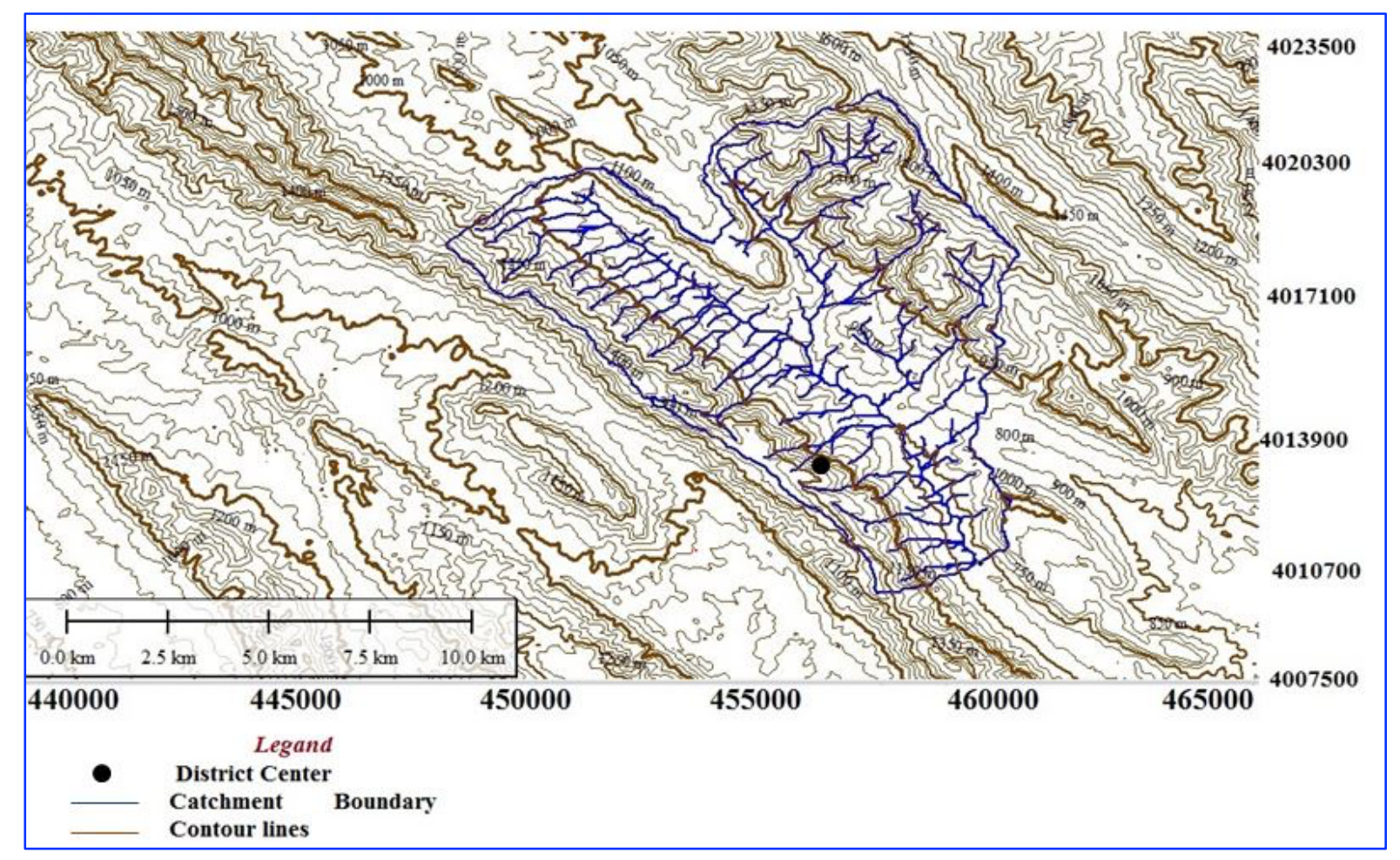

Fig. 2. Delineated Nazanin watershed using WMS

\section{Mean Annual Precipitation}

Since the catchment area is ungagged station, the mean annual precipitation is obtained using 17 surrounding stations. Arc map 10.1 was provided to create rainfall contour for the catchment area (Fig. 3). The mean annual rainfall depth at the site was found using Isohyet method (680 $\mathrm{mm})$.

\section{Annual Runoff}

The annual runoff is calculated from AL-Khazer average monthly inflow hydrograph. The ratio of area between AL-Khazer and Nazanin watershed is 0.023 and the ratio of annual rainfall is 0.973 , the catchment area relation is 0.022 . Based on this concept direct runoff ordinates SCS method is applied to calculate volume of runoff, the daily rainfall for the catchment was found by multiplying daily rainfall of Erbil station by a factor of 1.8. This factor is obtained from average precipitation of Nazanin / average precipitation of Erbil). The mean annual volume of runoff obtained using SCS method is $8036288 \mathrm{~m}^{3}$ while, mean annual runoff volume is 
$12813523 \mathrm{~m}^{3}$ using basin relationships with AL-Khazer.DRO, average monthly volume and depth of runoff for Nazanin stream is obtained (Table 1).

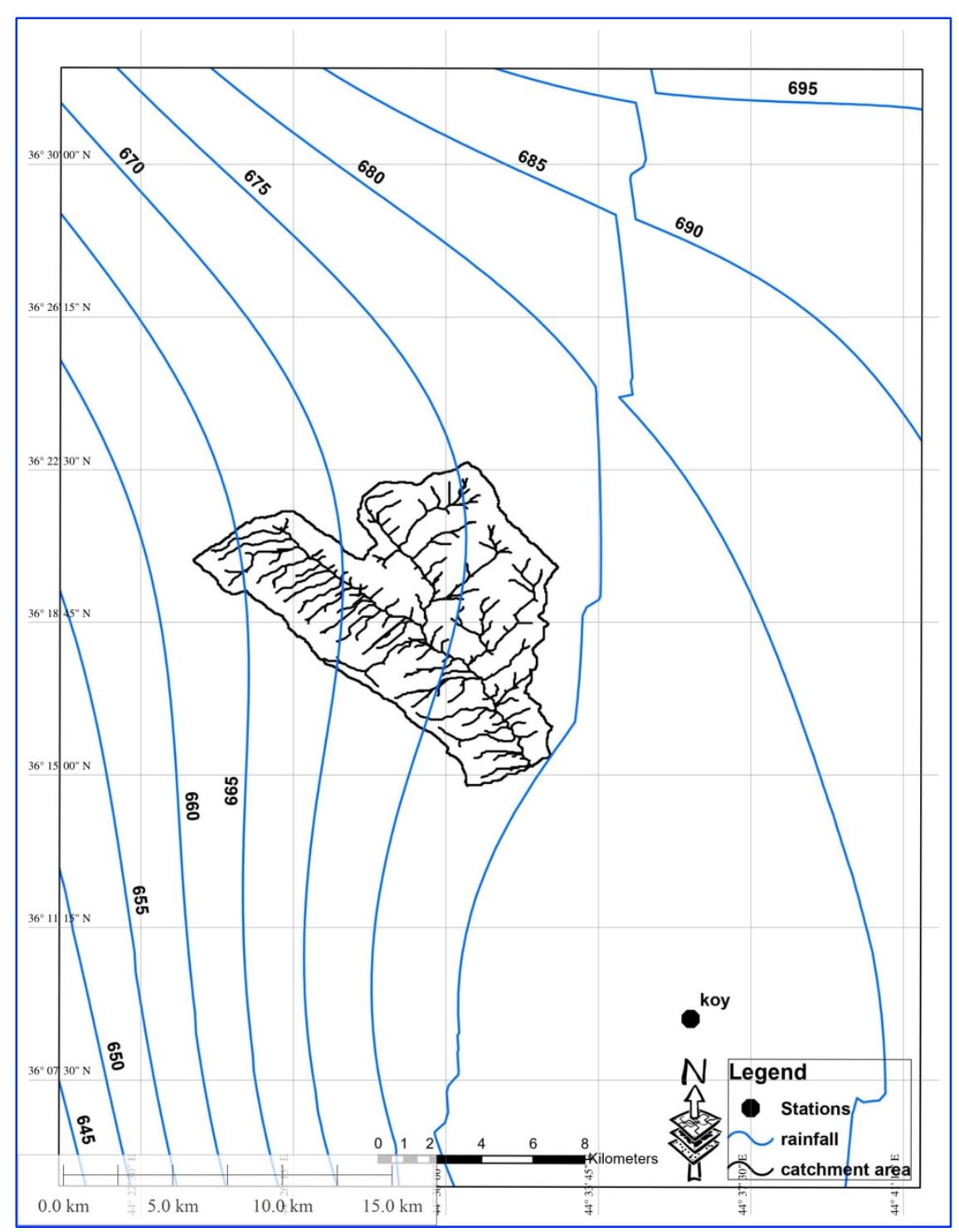

Fig. 3. Rainfall contour at the watershed

Table 1. Monthly runoff at Nazanin catchment using basin relation with Al Khazer

\begin{tabular}{|c|c|c|c|c|c|c|c|c|c|c|c|c|}
\hline Months & Sep & Oct & Nov & Dec & Jan & Feb & Mar & Apr & May & Jun & July & Aug \\
\hline DRO m m/s - Nazanin & 0 & 0 & 0.12 & 0.46 & 0.59 & 1.08 & 1.34 & 0.98 & 0.37 & 0 & 0 & 0 \\
\hline Volume of DRO $\mathrm{m}^{3}$ & 0 & 0 & 312957 & 1192780 & 1535261 & 2798899 & 3466146 & 2539085 & 968395 & 0 & 0 & 0 \\
\hline Depth of runoff- mm & 0 & 0 & 4.28 & 16.31 & 20.99 & 38.27 & 47.39 & 34.72 & 13.24 & 0 & 0 & 0 \\
\hline
\end{tabular}

As can be seen from results of mean annual runoff using basin relationship with Al-Khazer, it is higher than that using SCS method, this could be related to that in basin relation there is no any measure to take account the effect of land cover, land use, lithology and soil type in the equation. 


\section{Peak Discharge}

For determination peak discharge at Nazanin catchment area at different return period, three methods were applied, the basin relationships with Al-Khazer, SCS method and HEC-HMS model, the results of different methods were compared. In basin relationship method, peak discharges for different return periods were calculated using extreme Gumbel method, and then used to find peak discharge for Nazanin watershed (Table 2). In SCS method the time to peak was estimated which is 2.53 hour. The results of peak discharge using SCS method and both HEC-1 and HEC-HMS models are presented in Table 3.

Table 2. Peak discharge of Nazanin watershed using basin relationship

\begin{tabular}{|c|c|c|}
\hline $\begin{array}{c}\text { Return period } \\
\text { (Year) }\end{array}$ & $\begin{array}{c}\text { Q Peak AL- } \\
\text { Khazer }\left(\mathrm{m}^{3} / \mathrm{s}\right)\end{array}$ & $\begin{array}{c}\text { Q Peak Nazanin } \\
\left(\mathrm{m}^{3} / \mathrm{s}\right)\end{array}$ \\
\hline 2 & 601.7 & 66 \\
\hline 5 & 1038.9 & 113 \\
\hline 10 & 1328.5 & 145 \\
\hline 25 & 1694.3 & 185 \\
\hline 50 & 1965.7 & 214 \\
\hline 100 & 2235.1 & 244 \\
\hline 200 & 2503.4 & 273 \\
\hline 500 & 2857.5 & 312 \\
\hline 1000 & 3125.1 & 341 \\
\hline
\end{tabular}

Table 3. Results of peak discharge using SCS method, HEC-1 and HEC-HMS models

\begin{tabular}{|c|c|c|c|}
\hline $\begin{array}{c}\text { Return period } \\
\text { (Year) }\end{array}$ & $\begin{array}{c}\text { SCS } \\
\left(\mathbf{m}^{\mathbf{3}} \mathbf{s}\right)\end{array}$ & $\begin{array}{c}\text { HEC-1 } \\
\mathbf{( \mathbf { m } ^ { 3 } / \mathbf { s } )}\end{array}$ & $\begin{array}{c}\text { HEC-HMS } \\
\left(\mathbf{m}^{\mathbf{3}} / \mathbf{s}\right)\end{array}$ \\
\hline 2 & 163.67 & 168 & 168.8 \\
\hline 5 & 258.22 & 265.13 & 266.4 \\
\hline 10 & 324.85 & 333.63 & 335.1 \\
\hline 25 & 412.21 & 423.45 & 425.3 \\
\hline 50 & 478.75 & 491.87 & 493.9 \\
\hline 100 & 545.93 & 560.93 & 563.2 \\
\hline 200 & 613.77 & 630.71 & 633.2 \\
\hline 500 & 704.41 & 723.91 & 726.7 \\
\hline 1000 & 773.62 & 795.07 & 798.1 \\
\hline
\end{tabular}

As can be observed from Tables 1 and 2, the result of SCS method and both models (HEC1 and HEC-HMS) are very close to each other, while results of peak discharge obtained from basin relationship are underestimate at all return periods. There is a small difference between SCS method, HEC-1 and HEC-HMS models, this difference is mainly related to the 
type of rainfall distribution. HEC-1 model results are closer to the SCS method than HECHMS. The results of flood hydrograph of 100 years return period that predicted by SCS method, HECHMS and HEC-1 models are shown in Figs. 4 and 5. From both graphs it is clear that the flood hydrographs that generated using HECHMS and HEC-1 models are very close to that predicted by SCS method.

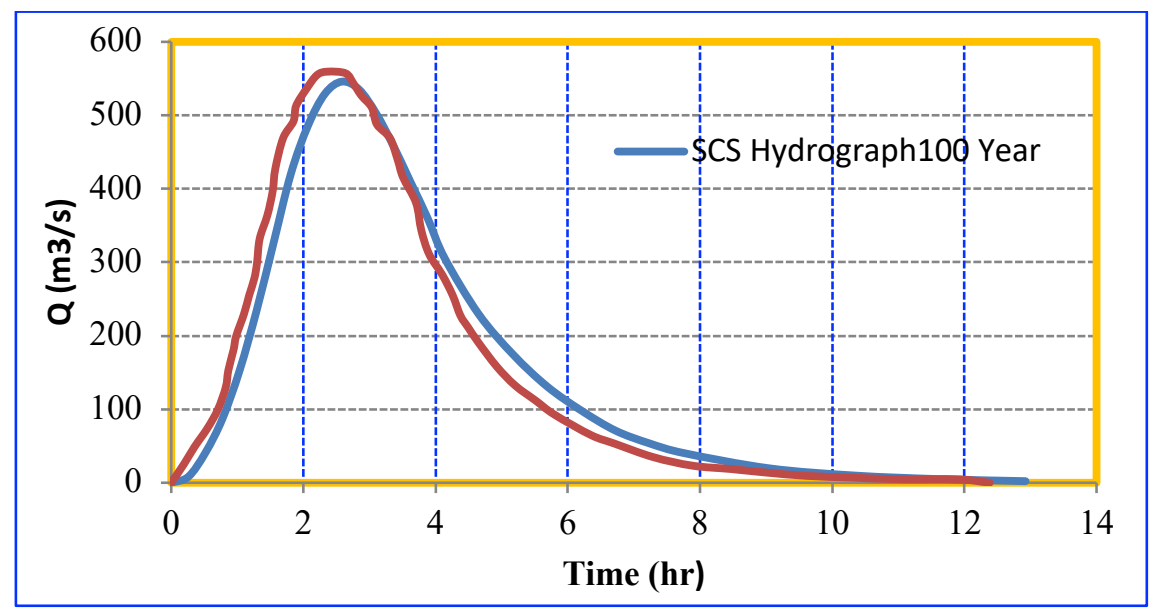

Fig. 4. Flood hydrograph generated by using HECHMS model and SCS method

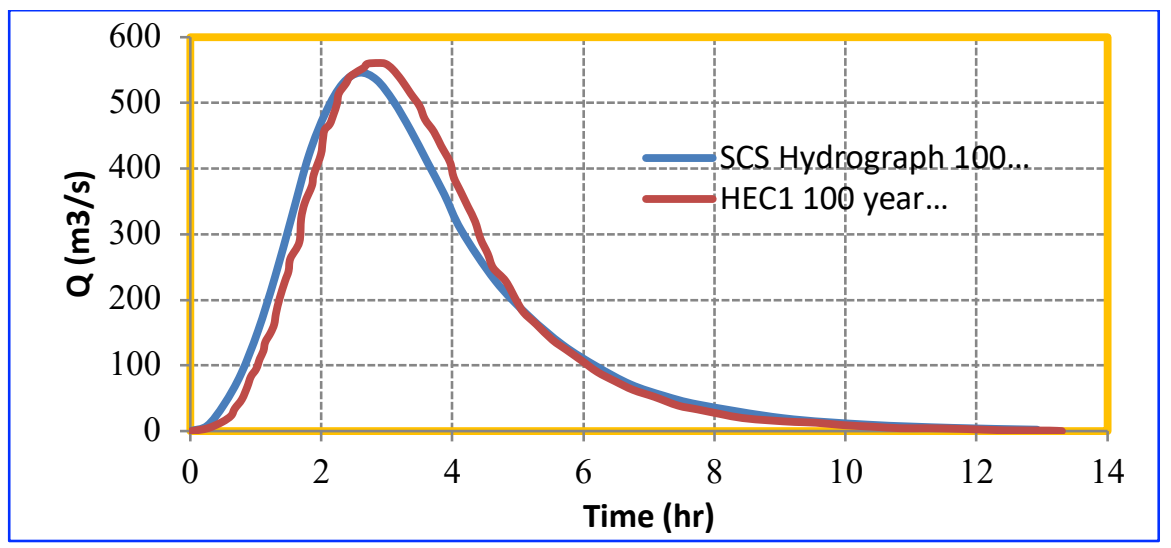

Fig. 5. Flood hydrograph generated by using HEC-1 model and SCS method

\section{CONCLUSIONS}

In the present study, four approaches were provided for calculation peak flood discharge and mean annual runoff for Nazanin catchment area which is an ungagged catchment and concluded as follows.

1. Both HEC-1 and HEC-HMS models could accurately predict of peak flood discharge in comparison with SCS method.

2. SCS method is an efficient approach in predicting peak flood discharge at ungagged catchment area. 
3. HEC-HMS and HEC-1 model generated flood hydrograph accurately.

4. Basin relation approach results are underestimating in predicting peak flood discharge.

\section{ACKNOWLEDGMENTS}

The authors are very grateful to the Editor in Chief Prof. Dr. Salih M. Awadh, the Secretary of Journal Mr. Samir R. Hijab and the Technical Editor Dr. Heba S. Al-Mimar for their great efforts and valuable comments.

\section{REFERENCES}

Awadh, S., M., and Ahmad, L., M., 2012. Climatic prediction of the terrestrial and coastal areas of Iraq. Arabian Journal of Geosciences, 5: 465-469, DOI 10.1007/s12517-010-0257-4.

Awadh, S., M., and Abdul Al-Qhani, S. 2014. Assessment of sulfurous springs in the west of Iraq for balneotherapy, drinking, irrigation and aquaculture purposes, Environ Geochem Health (2014) 36:359373, DOI 10.1007/s10653-013-9555-6.

Chow, V.T., Maidment, D.R. and Larry, W., 1988. Mays. Applied Hydrology. International edition, MacGrawHill, Inc, 149.

Fathy, I., Negm, A.M., El-Fiky, M., Nassar, M. and Al-Sayed, E., 2015. Runoff hydrograph modeling for arid regions: case study, Wadi Sudr-Sinai. International Water Technology Journal. 5(1): 58-68.

Hoseini, Y., Azari, A. and Pilpayeh, A., 2017. Flood modeling using WMS model for determining peak flood discharge in southwest Iran case study: Simili basin in Khuzestan Province. Applied Water Science, 7(6): 3355-3363.

Heedan, M.O., Bapeer, G.B. and Khodakarami, L., 2017. Estimation the Volume of Runoff using natural resources conservation service method and geographic information system in Koya basin, Sulaimaniya, Iraq. Iraqi Geological Journal, 50 (2): 100-120.

Lettenmaier, D. P. and Burges, S. J., 1982. Gumbel's extreme value. I. Distribution: A new look. ASCE Journal of Hydrology.108(HY4): 502-514.

Oleyiblo, J. O. and Li, Z. J., 2010. Application of HEC-HMS for flood forecasting in Misai and Wan'an catchments in China. Water Science and Engineering, 3(1):14-22.

Paudel, M., Nelson, E. J., Downer, C.W. and Hotchkiss, R., 2011. Comparing the capability of distributed and lumped hydrologic models for analyzing the effects of land use change. Journal of hydroinformatics, 13(3): 461-473.

Sajikumar, N. and Thandaveswara, B. S., 1999. A non-linear rainfall-runoff model using an artificial neural network. Journal of Hydrology, 216 (1-2): 32-55.

Shi, Z. H., Chen, L. D., Fang, N. F., Qin, D. F. and Cai, C. F., 2009. Research on the SCS-CN initial abstraction ratio using rainfall-runoff event analysis in the Three Gorges Area, China. Catena, 77(1): 1-7.

Shultz, M. J., 2008. Comparison of distributed versus lumped hydrologic simulation models using stationary and moving storm events applied to small synthetic rectangular basins and an actual watershed basin.

Steenhuis, T. S., Winchell, M., Rossing, J., Zollweg, J. A. and Walter, M. F., 1995. SCS runoff equation revisited for variable source runoff areas. Journal of Irrigation and Drainage Engineering. 121(3): 234-238.

Talei, A., Chua, L. H. C. and Quek, C., 2010. A novel application of a neuro-fuzzy computational technique in event-based rainfall-runoff modeling. Expert Systems with Applications, 37(12): 7456-7468.

Tsheko, R., 2006. Comparison between the United States Soil Conservation Service (SCS) and the two models commonly used for estimating rainfall-runoff in south-eastern Botswana. Water SA. 32(1): 29-36.

Yannopoulos, S., Katsi, A. and Papamichail, D., 2006. Comparative analysis of synthetic unit hydrograph methods using WMS rainfall-runoff process simulation.

Younis, A. M., Hasan, I. F. and Saeed, Y. N., 2014. Comparison study of two methods used to estimate surface runoff hydrograph for Smal Basins. Journal of Engineering and Sustainable Development. 18(6): 218-232.

Zhang, X., Srinivasan, R., Debele, B. and Hao, F., 2008. Runoff simulation of the headwaters of the yellow river using The SWAT model with three snowmelt algorithms. Journal of the American Water Resources Association,.44(1): 48-61. 